References

1 O'Callaghan C, McDougall P. Infective endocarditis in neonates. Arch Dis Child 1988;63:53-7.

2 Oelberg DG. Endocarditis in high risk neonates. Pediatrics 1983:71:392-7.

M J BanNon
Our Lady's Hospital for Sick Children,
Crumlin,
Dublin

\section{Varicella gangrenosa}

Sir,

We read with great interest the account of a case of varicella gangrenosa by Kidney et $\mathrm{al}^{1}$ and would like to report our experience with a similar case associated with an unusual complication.

\section{Case report}

A $3 \frac{1}{2}$ year old girl developed pain in her left leg eight days after chickenpox, when her chickenpox lesions were actually drying up. A couple of days later her parents noticed a few large, dark bruises appearing on her left leg. On examination she looked rather pale with a normal pulse rate and blood pressure. She had three large, dark, and tender ecchymotic areas on her left leg and similar, smaller lesions, one on each side, just above the ankle. The left leg was obviously swollen and she was unable to bear weight on that leg. Her peripheral pulses were normally palpable.

Initial investigations showed a mild anaemia (haemoglobin $100 \mathrm{~g} / \mathrm{l}$ ) with normal white cell and platelet counts. The prothrombin activity was reduced to $70 \%$. Cephalin-kaolin time increased to 52 seconds and fibrinogen degradation products were $>40 \mathrm{mg} / \mathrm{l}$ (normal $<10 \mathrm{mg} / \mathrm{l}$ ).

Despite fresh frozen plasma $(10 \mathrm{ml} / \mathrm{kg})$ her bruises increased in size in the $\mathbf{2 4}$ hours after admission. She was, therefore, started on prednisolone $2 \mathrm{mg} / \mathrm{kg} /$ day which seemed to control the spread of the skin lesions and the leg swelling. Her steroid dose was reduced, from the fourth day after admission, but on the fifth day she suddenly developed severe abdominal pain requiring a pethidine injection. She had tenderness in both renal angles and urine examination showed a few red blood cells but no protein. An intravenous pyelogram showed enlargement of both kidneys (left more than right). The right nephogram appeared immediately, the left slowly evolved over 5-10 minutes and the pyelogram on the left was also delayed, beginning to appear after 20 minutes. These findings added support to the clinical suspicion of a renal vasculitis and, probably, a renal vein thrombosis.

She failed to pass urine for 10 hours but, subsequently, produced urine normally. Blood pressure, urea, and electrolytes also remained normal. Plasma proteins and complement concentrations were normal and antiDNA antibodies were negative. Her symptoms quickly improved with intravenous dextrose saline infusion to maintain hydration, continued use of steroids, and intravenous ampicillin. We did not give anticoagulant treatment. The skin lesions became blistery after a few days; this was followed by thick eschar formation. This needed applica- tion of streptokinase-streptodornase to remove the scab. It took about six weeks for the lesions to heal completely and they had left rather unsightly scars on the left thigh, tethered down to the underlying fascia.

\section{Reference \\ ${ }^{1}$ Kidney DD, Watson JBG, Nisar N. Varicella gangrenosa. Arch Dis Child 1988;63:444-5.}

K K SingH

Rochford Hospital, Rochford, Essex

D O Hughes

Ormskirk and District General Hospital,

Ormskirk,

Lancashire

\section{Very young children and the Family Fund}

Sir,

When the Family Fund, which gives modest grants to families with severely handicapped children, started in 1973 its advisers almost ruled that no child under 2 years of age could satisfy the medical criteria. ${ }^{1}$ Fortunately the possibility was left open and a small number of multiply handicapped babies, being nursed at home, have always been accepted.

In recent years, however, the Fund is receiving applications for and accepting as eligible an increasing number of such babies. In 1981 there were 920 applications on behalf of children under 2 and $50 \%$ of these infants were regarded as sufficiently handicapped to be eligible. By 1987 the number of applications had almost doubled and two thirds of them were accepted.

Developments in medical techniques and the increased possibility of litigation if a consultant is not seen to do his utmost to save life mean that more babies born with disabilities are surviving, and more who are born prematurely survive but develop disabilities in their struggle to hang on to life. More significant, from the point of view of the Family Fund, is the fact that such babies are often returned to the care of their parents, even when they require 24 hours nursing.

Research evidence has shown that there are considerable financial costs in caring for a disabled child at home ${ }^{2}$ and the government, in recently announcing the possible extension of attendance allowance to children under 2 , has acknowledged that the actual problems of care of such a child are significantly more than that of a normal baby. ${ }^{3}$ It is vital that professionals should realise that the Family Fund has always recognised this and that families are not discounted because the child is not yet 2 years old

\section{References}

1 Bradshaw J. The Family Fund. London: Routledge and Kegan Paul, 1980.

2 Baldwin S. The costs of caring. London: Routledge and Kegan Paul, 1985. 
${ }^{3}$ Lewis J. New help for disabled babies. New Society 1988;1309:5.

E M BARNes and D LAwToN Social Policy Research Unit, University of York, Heslington, York YO1 5DD

\section{Computed tomography in childhood epilepsy}

Sir,

Children attending the school at the David Lewis Centre for Epilepsy are a selected group, as with few exceptions they are residential pupils from various parts of the United Kingdom and therefore are likely to have severe and often multiple handicaps. It seemed probable that a group of such children might show a high incidence of significant abnormalities on computed tomography.

The children attending the school at the David Lewis Centre and examined by computed tomography over several years numbered 222; there were 154 boys and 68 girls, aged 7 to 19 years. The results showed that 152 were normal. There were 28 with evidence of some degree of generalised atrophy and 30 with focal atrophy. Nine showed calcification and in three the findings were compatible with a cerebral tumour. Abnormalities in a third of the children is in agreement with the findings of Bachman et al ${ }^{1}$ and Yang et al. ${ }^{2}$ Bachman et al studied 98 children with chronic seizure disorders, and computed tomograms identified structural abnormalities in 30\%, almost half having generalised or focal atrophy. Two per cent showed possible evidence of unsuspected cerebral tumours. In the study of Yang et al, 256 computed tomograms were performed to aid the evaluation of children with seizure disorders. There were abnormalities in $33 \%$ that were found mainly among those with partial seizures and generalised seizures of known aetiology, but also in those with neonatal seizures and in those with abnormal neurological findings and focal slowing shown on electroencephalography. Five patients were found to have cerebral tumours, one a porencephalic cyst, and one extraventricular communicating hydrocephalus. The use of computed tomography among children with non-specific mental retardation also seems to be unhelpful, ${ }^{3}$ but when the mental retardation is associated with infantile spasms the scan is often abnormal, showing evidence of tuberous sclerosis or agenesis of the corpus callosum. ${ }^{4}$

Therefore it seems unlikely that a selected group of children such as those attending a special residential school will show more abnormalities than those seen in hospital outpatient clinics. Also the use of routine computed tomography in the investigation of children with epilepsy seems unjustified, although it will be indicated if there are symptoms and signs suggestive of a focal lesion. Twenty two children who showed thickening of the skull vault, and often proliferation of the intracranial sinuses, and 25 children with evidence of cerebral atrophy were assessed for correlations with the antiepileptic drugs that had been given and with the possible timing of the damage to the brain. Phenytoin and carbamazepine had been given to an equal number in both groups, which did not support the role of these drugs in causing thickening of the skull bones. The onset of seizures was more frequent during the first year in the first group, which may suggest an impairment of cerebral development at an early stage, which is also indicated by the thickening of the bones.

\section{References}

${ }^{1}$ Bachman DS, Hodges FJ, Freeman JM. Computerized axial tomography in chronic seizure disorders in childhood. Pediatrics 1976;58:828-32.

2 Yang PY, Berger PE, Cohen ME, Duffner PK. Computed tomography and childhood seizure disorders. Neurology 1979;29:1084-8.

3 Lingham S, Read S, Holland IM, Wilson J, Brett EM, Hoare RD. Value of computerised tomography in children with nonspecific mental subnormality. Arch Dis Child 1982;57: 381-3.

4 Lingham S, Kendall BE. Computed tomography in non-specific mental retardation and epilepsy. Arch Dis Child 1983;58: $628-43$.

Booth Hall Children's Hospital, Blackley, Manchester M9 2AA

\section{Henoch-Schönlein purpura secondary to trauma}

Sir,

The aetiology of Henoch-Schönlein purpura (HSP) is controversial. Various bacterial and viral infections together with drug and food sensitivity have been identified as possible aetiological factors. ${ }^{1}$ No mention of trauma as a causative agent has been found in the literature. It is postulated that a traumatic event produces a shower of antigenic material of joint contents or tissue breakdown products which may initiate HSP.

We describe two cases where trauma preceded the symptoms of HSP.

\section{Case reports}

\section{CASE 1}

A 2 year old boy was brought to casualty with a limp after a fall the previous day. He had a swollen and tender right ankle. Radiological investigation showed an undisplaced fracture of the metaphysis of the right fibula. He was treated conservatively and later discharged. Two days later he returned to casualty with a painful left ankle. He was irritable, his temperature was $37 \cdot 1^{\circ} \mathrm{C}$, and he had a maculopapular rash. HSP was diagnosed and subsequently he developed abdominal discomfort, lymphadenopathy, proteinuria, and purpura. The bruise overlying his right ankle was yellow whereas the purpura of the HSP were blue/black. 